\title{
The freshwater crabs of Macau, with the description of a new species of Nanhaipotamon Bott, 1968 and the redescription of Nanhaipotamon wupingense Cheng, Yang, Zhong \& Li, 2003 (Crustacea, Decapoda, Potamidae)
}

\author{
Chao Huang ${ }^{1,2,3}$, Kai Chin Wong 4 , Shane T. Ahyong ${ }^{1,2}$ \\ I Palaeontology, Geobiology and Earth Archives Research Centre, School of Biological, Earth and Environmen- \\ tal Sciences, University of New South Wales, Kensington, NSW 2052, Australia 2 Australian Museum, 1 Wil- \\ liam St, Sydney NSW 2010, Australia 3 School of Life Sciences, Sun Yat-sen University, Guangzhou 510275, \\ China 4 Macao Civic and Municipal Affairs Bureau, Macao SAR, China \\ Corresponding author: Shane T. Ahyong (shane.ahyong@austmus.gov.au)
}

Academic editor: S. De Grave | Received 21 October 2018 | Accepted 26 November 2018 | Published 20 December 2018

http://zoobank.org/2A23FBC5-0BFD-4665-8FDB-12CF86E8FCC3

Citation: Huang C, Wong KC, Ahyong ST (2018) The freshwater crabs of Macau, with the description of a new species of Nanhaipotamon Bott, 1968 and the redescription of Nanhaipotamon wupingense Cheng, Yang, Zhong \& Li, 2003 (Crustacea, Decapoda, Potamidae). ZooKeys 810: 91-111. https://doi.org/10.3897/zookeys.810.30726

\begin{abstract}
Four species of freshwater crabs from three genera and two families (Cantopotamon hengqinense Huang, Ahyong \& Shih, 2017, Nanhaipotamon guangdongense Dai, 1997, Nanhaipotamon macau sp. n., and Somanniathelphusa zanklon $\mathrm{Ng} \&$ Dudgeon, 1992) are documented from Macau for the first time. One new species, Nanhaipotamon macau sp. n., is described. The large flap on the male first gonopod terminal segment sets it apart from all other known congeners except $N$. wupingense Cheng, Yang, Zhong \& $\mathrm{Li}$, 2003, from Fujian. Characters of the carapace, male first gonopod and size, however, clearly differentiate these two species. Preliminary genetic studies also suggest that the two are not closely related. A neotype is designated for N. wupingense. The taxonomic status of Nanhaipotamon guangdongense is also discussed. Notes on the general biology and conservation status of these crabs are also included.
\end{abstract}

\section{Keywords}

Freshwater crabs, Gecarcinucidae, Macau, new species, Potamidae, systematics

Copyright Chao Huang et al. This is an open access article distributed under the terms of the Creative Commons Attribution License (CC BY 4.0), which permits unrestricted use, distribution, and reproduction in any medium, provided the original author and source are credited. 


\section{Introduction}

Best known as the gambling capital of the world, Macau (also known as Macao) has a total land area of only $30.8 \mathrm{~km}^{2}$ but a population of more than 650,000 people, making it one of the most densely populated regions in the world (Government of Macao Special Administrative Region Statistics and Census Service). Macau historically consists of the Macau Peninsula (bordered by Zhuhai to the north) and two islands: Taipa and Coloane. The two islands are now joined by Cotai, an area created by land reclamation in 2005 .

The freshwater crabs of Macau have not been scientifically documented to the best of our knowledge. General wetland faunal surveys from 2007 onwards have found freshwater crabs in Coloane resulting in a small collection kept in the Macao Civic and Municipal Affairs Bureau. Upon examination, it was found that these freshwater crab specimens contained three species, Cantopotamon hengqinense Huang, Ahyong \& Shih, 2017, Somanniathelphusa zanklon Ng \& Dudgeon, 1992, and a new species of Nanhaipotamon Bott, 1968. This has led to more extensive surveys in 2018, covering 14 survey points (two in Taipa and 12 in Coloane; Fig. 1) focused exclusively on freshwater crabs. Three species of potamid crabs, Cantopotamon hengqinense Huang, Ahyong \& Shih, 2017, Nanhaipotamon guangdongense Dai, 1997, and Nanhaipotamon macau sp. n. and one species of gecarcinucid crab, Somanniathelphusa zanklon $\mathrm{Ng}$ \& Dudgeon, 1992, were found. Nanhaipotamon macau sp. n. is very similar to the poorly known, N. wupingense Cheng, Yang, Zhong \& Li, 2003, from Fujian Province. Unfortunately, the identity of $N$. wupingense is ambiguous because the type account is inadequate and the type material lost, requiring a neotype designation.

\section{Materials and methods}

Specimens were collected by hand and preserved in 75\% ethanol from 2007 onwards from South China. They are deposited in the Sun Yat-sen Museum of Biology, Sun Yat-sen University, Guangzhou, China (SYSBM); the Australian Museum, Sydney, Australia (AM); the Zoological Reference Collection of the Lee Kong Chian Natural History Museum, National University of Singapore, Singapore (ZRC); and the Macao Civic and Municipal Affairs Bureau (IACM). Measurements, in millimetres, are of the carapace width and length, respectively. Other abbreviations are as follows:

G1 male first gonopod;

G2 male second gonopod;

CW carapace width.

The terminology used primarily follows that of Dai (1999) and Davie et al. (2015). The Kimura 2-parameter (K2P) COI sequence distances (Kimura 1980) were calculated using MEGA6 (Tamura et al. 2013). H-T Shih kindly provided the COI sequence data of various species of Nanhaipotamon for use in this study (GenBank accession nos. MK226142-MK226145). 


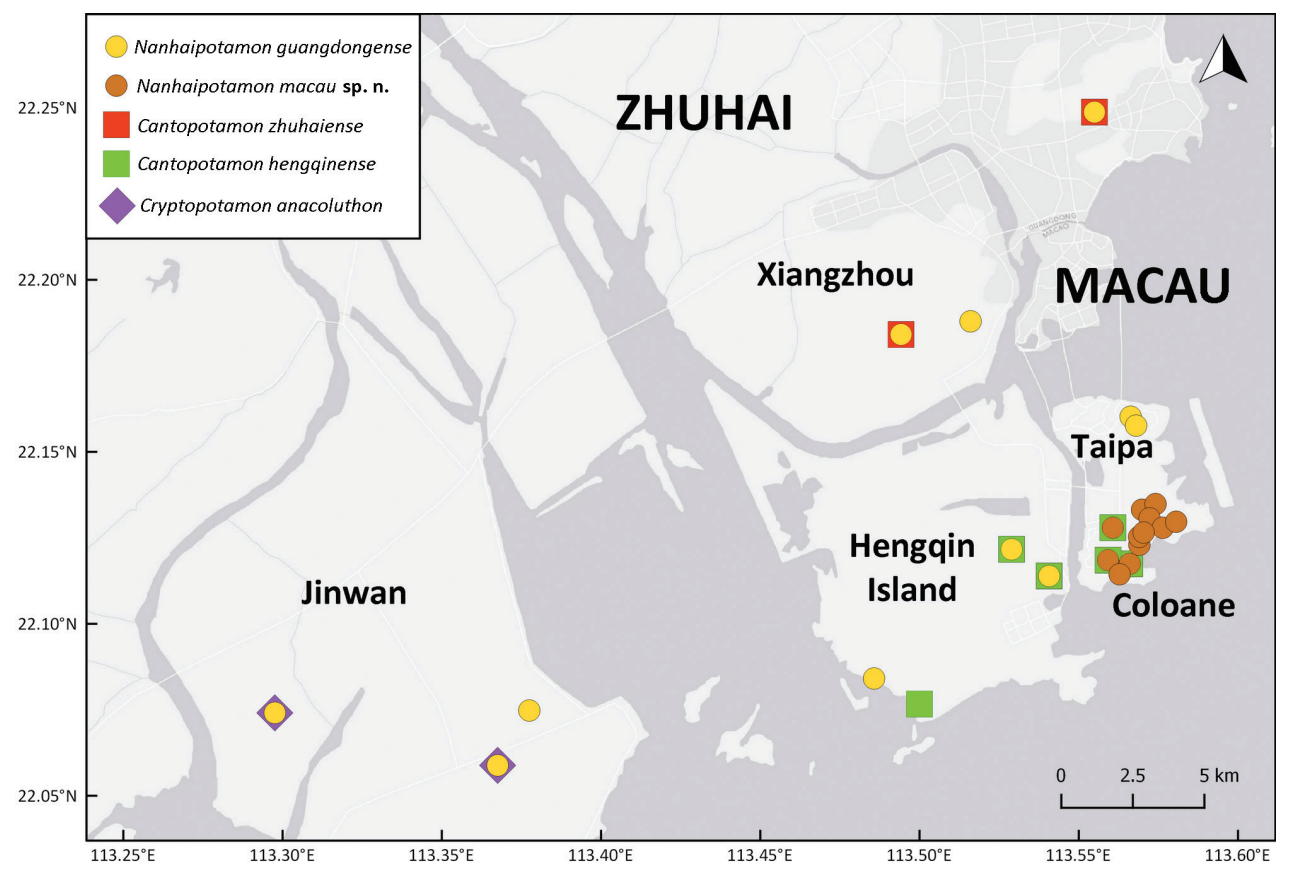

Figure I. Localities of the sampling sites in and around Macau.

\section{Taxonomy}

Family Potamidae Ortmann, 1896

Subfamily Potamiscinae Bott, 1970

Genus Cantopotamon Huang, Ahyong \& Shih, 2017

Cantopotamon hengqinense Huang, Ahyong \& Shih, 2017

Fig. 2C

Cantopotamon hengqinense Huang, Ahyong \& Shih, 2017: 9, fig. 5.

Type material. Holotype: SYSBM 001558, male $(19.9 \times 16.0 \mathrm{~mm})$, Dahengqin Mountain $(22.11 \mathrm{~N}, 113.50 \mathrm{E})$, Hengqin Island, Zhuhai City, Guangdong, China, small hillstream, under rocks, coll. C. Huang, February 2016. Paratypes: SYSBM 001559, 1 female $(13.0 \times 10.6 \mathrm{~mm})$, same data as holotype. SYSBM 001560-001561, 2 males $(15.5 \times 12.4 \mathrm{~mm}, 13.2 \times 10.7 \mathrm{~mm})$, same data as holotype.

Other material examined. China: IACM, 2 males $(20.5 \times 16.5 \mathrm{~mm}, 19.5 \times$ $16.5 \mathrm{~mm})$, Coloane $(22.12 \mathrm{~N}, 113.56 \mathrm{E})$, Macau, small hillstream, under rocks, coll. K.C. Wong, November 2009. SYSBM 001640, 1 male $(17.5 \times 13.6 \mathrm{~mm})$, Dahengqin Mountain, Hengqin Island, Zhuhai City, Guangdong, small hillstream, under rocks, coll. C. Huang, August 2017. SYSBM 001641-1644, 4 females $(20.5 \times 16.0$ $\mathrm{mm}, 15.1 \times 11.8 \mathrm{~mm}, 14.1 \times 10.8 \mathrm{~mm}, 12.3 \times 10.0 \mathrm{~mm})$, same as SYSBM 001640 . ZRC, 1 male $(19.7 \times 15.4 \mathrm{~mm})$, Coloane, Macau, small hillstream, under rocks, coll. 


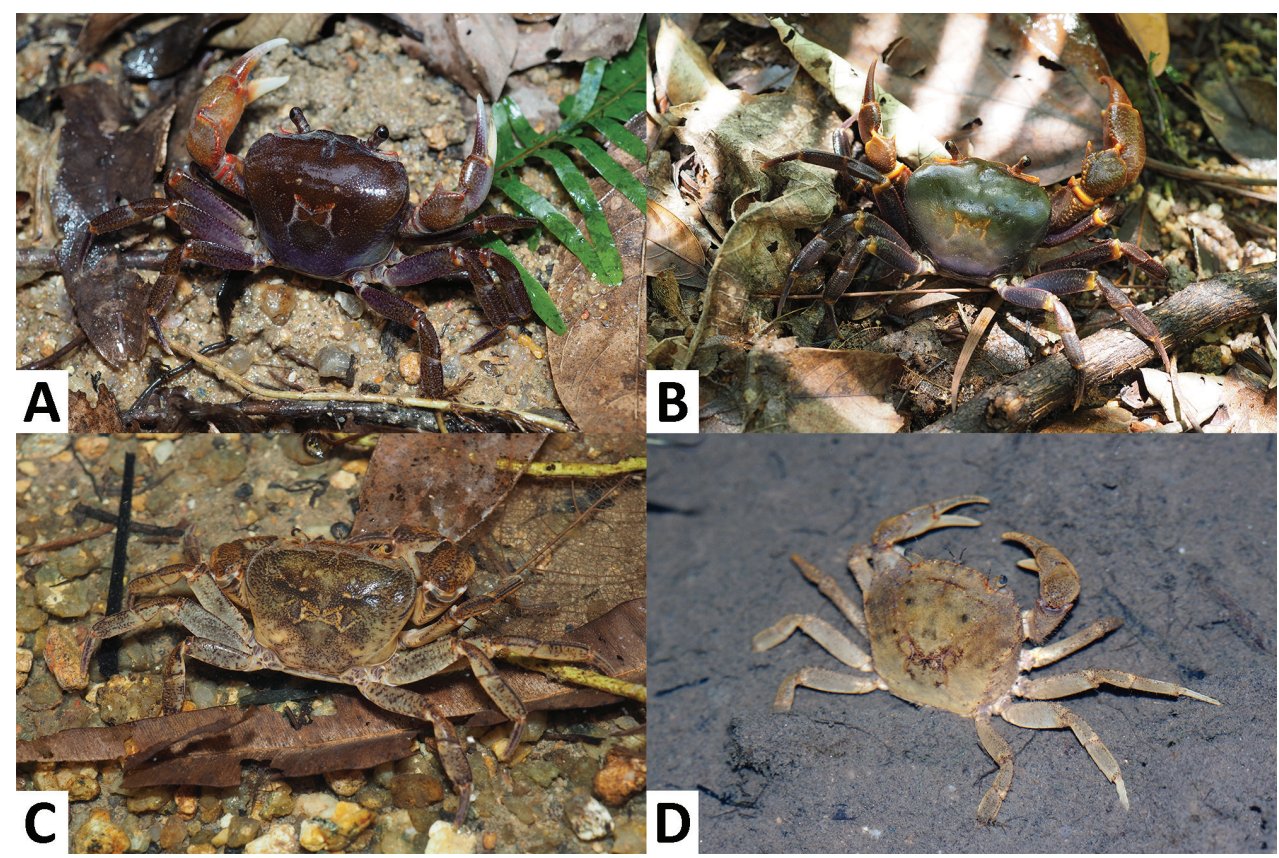

Figure 2. The freshwater crabs of Macau, colour in life. Nanhaipotamon macau sp. n., male $(29.0 \times 24.2$ mm), SYSBM 001654 (A); Nanhaipotamon guangdongense Dai, 1997, male (35.9 × 28.8 mm), SYSBM 001645 (B); Cantopotamon hengqinense Huang, Ahyong \& Shih, 2017, male, specimen not collected (C); Somanniathelphusa zanklon Ng \& Dudgeon, 1992, photographed in Zhuhai, specimen not collected (D).

C. Huang, January 2018. ZRC, female $(16.7 \times 13.2 \mathrm{~mm})$, same data as above. AM P101300, male $(19.0 \times 15.4 \mathrm{~mm})$, Coloane, Macau, small hillstream, under rocks, coll. C. Huang, February 2018.

Distribution. Hengqin Island, Zhuhai, Guangdong; Coloane, Macau.

Conservation status. Cantopotamon hengqinense was previously only known from three hill streams in Dahengqin Mountain in Hengqin Island. This study found it to be present in another three hill streams in the neighbouring southwest corner of Coloane, Macau, which extends its extent of occurrence to $34.6 \mathrm{~km}^{2}$ (excluding sea area), area of occupancy to $11.7 \mathrm{~km}^{2}$ and number of locations to two. The populations in Hengqin and Macau are currently isolated from each other by a narrow strip of sea. Unlike the Hengqin population, whose habitat is threatened by urban development (Huang et al. 2017), the Macau population does not face serious imminent threat as all localities at which it was found are not currently open to development. Specimens from Macau are morphologically indistinguishable from those found in Hengqin Island. Cantopotamon hengqinense has not been found in Xiangzhou, Zhuhai to the north and Sanzao Island to the west despite considerable survey efforts during 2011-2018. In fact, no species of Cantopotamon are known from Sanzao Island, where instead Cryptopotamon anacoluthon (Kemp, 1918) is abundant. Given that the extent of occurrence and area 
of occupancy of $C$. hengqinense is much lower than $5,000 \mathrm{~km}^{2}$ and $5000 \mathrm{~km}^{2}$, respectively, with fewer than five known locations and projected decline in habitat quality in Hengqin, the suggested corresponding conservation status of this species under IUCN Red List criteria remains as indicated by Huang et al. (2017), as Endangered B2(a)(b).

\section{Genus Nanhaipotamon Bott, 1968}

\section{Nanhaipotamon macau sp. $\mathbf{n}$.}

http://zoobank.org/550E7796-5748-4522-9825-C2A6EDB3BD8B

Figs 2A, 3-5, 6A-C

Type material. Holotype: SYSBM 001649, male $(37.4 \times 30.9 \mathrm{~mm})$, Coloane $(22.12 \mathrm{~N}$, 113.56E), Macau, China, forest floor, coll. K.C. Wong, July 2010. Paratypes: SYSBM 001650, female $(31.3 \times 25.5 \mathrm{~mm})$, Coloane, Macau, China, mud burrow adjacent to small hill stream, coll. C. Huang, February 2018. SYSBM 001651, male $(36.6 \times$ $29.3 \mathrm{~mm})$, same data as above. IACM, 2 males $(36.5 \times 31.1 \mathrm{~mm}, 34.6 \times 28.5 \mathrm{~mm})$, Coloane, Macau, forest floor, coll. J. Z. Huang, July 2009. AM P101301, male (27.7 × $22.9 \mathrm{~mm})$, same data as above. ZRC, male $(22.3 \times 19.0 \mathrm{~mm})$ Coloane, Macau, China, under rock in small hillstream, coll. C. Huang, January 2018.

Other material examined. Macau: SYSBM 001652-55, 4 males $(35.3 \times 28.8$ $\mathrm{mm}, 32.1 \times 26.5 \mathrm{~mm}, 29.0 \times 24.2 \mathrm{~mm}, 28.9 \times 24.1 \mathrm{~mm}$ ), Coloane, in burrows adjacent to small hill stream, coll. C. Huang, February 2018.

Diagnosis. Carapace broader than long, regions indistinct, dorsal surface convex, anterolateral region weakly rugose (Figs 3A, 4B); postorbital cristae sharp, laterally expanded, almost fused with epibranchial teeth and epigastric cristae (Figs 3A, 4B); external orbital angle sharply triangular, outer margin gently convex to almost straight, separated from anterolateral margin by conspicuous gap (Figs 3A, B, 4B); sub-orbital regions covered by sparse low granules, pterygostomial regions covered with short rows of a few rounded granules; sub-hepatic regions covered with lined striae (Fig. 3B); maxilliped III exopod reaching to proximal one-third of merus with short flagellum (Fig. 5A); female vulva ovate, medium-sized, positioned closely to one another (Fig. 4D); male pleon triangular, lateral margins almost straight (Fig. 3C); G1 slender, subterminal segment tapering distally, terminal segment large, distally expanded, distal margin laminar, apex blunt, directed outward (Figs 5C-E, 6A-C). G2 basal segment subovate (Fig. 5B).

Description. Carapace broader than long, width about $1.2 \times$ length $(n=6)$; regions indistinct, dorsal surface convex; surface generally smooth, pitted, anterolateral region weakly rugose (Figs 3A, 4B). Front deflexed, margin ridged in dorsal view (Figs 3A, 4B). Epigastric cristae low, separated by narrow gap (Figs 3A, 4B). Postorbital cristae sharp, laterally expanded, almost fused with epibranchial teeth and epigastric cristae (Figs 3A, 4B). Branchial regions slightly swollen (Figs 3A, B, 4B). Cervical groove shallow (Figs 3A, 4B). Mesogastric region slightly convex (Figs 3A, 4B). External orbital 


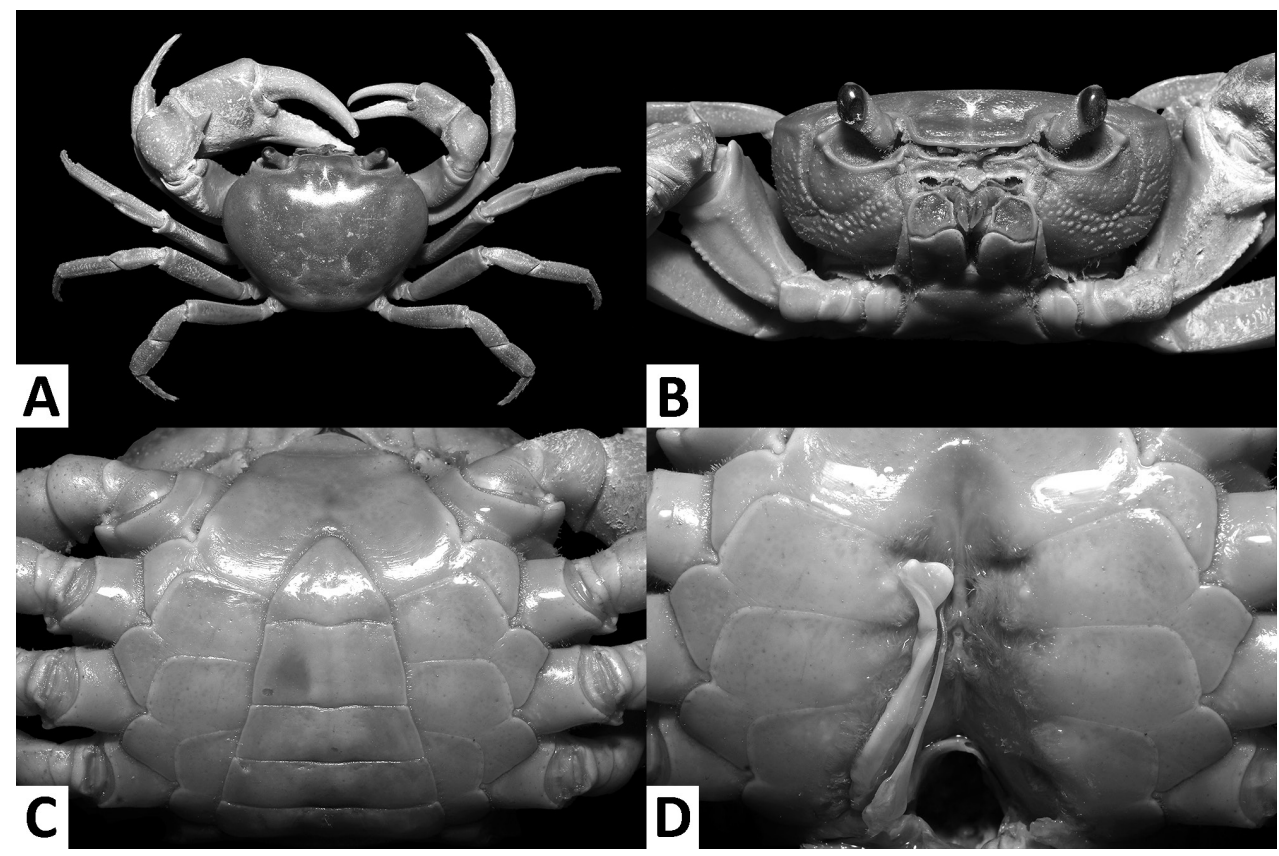

Figure 3. Nanhaipotamon macau sp. n., male holotype $(37.4 \times 30.9$ mm), SYSBM 001649 Dorsal habitus $(\mathbf{A})$; cephalothorax, anterior view (B); anterior thoracic sternum and pleon, ventral view (C); sternopleonal cavity with right G1 in situ (left G1 removed), ventral view (D).

angle sharply triangular, outer margin gently convex to almost straight, separated from anterolateral margin by conspicuous gap (Figs 3A, B, 4B). Epibranchial tooth small, granular, indistinct (Figs 3A, B, 4B). Anterolateral margin cristate, lined with 20-23 granules, less distinct in some larger specimens; bent inward posteriorly (Figs 3A, 4B). Posterolateral surface with low, oblique striae, converging towards posterior carapace margin (Figs 3A, 4B). Orbits large; supraorbital, infraorbital margins cristate (Fig. 3B). Sub-orbital regions covered by sparse low granules, pterygostomial regions covered with short rows of a few rounded granules; sub-hepatic regions covered with lined striae (Fig. 3B). Epistome posterior margin narrow; median lobe broadly triangular, lateral margins slightly sinuous (Fig. 3B).

Maxilliped III merus about as wide as long; ischium width about $0.7 \times$ length; merus subtrapezoidal, with median depression; ischium subtrapezoidal, with distinct median sulcus, mesial margin rounded. Exopod reaching to proximal one-third of merus; flagellum short (Fig. 5A).

Chelipeds (pereiopod I) unequal (Figs 3A, 5F-I); less inflated in females (Figs 4B, 5H, I). Merus trigonal in cross section; margins crenulated, dorsal-outer surface granulated. Carpus with sharp spine at inner-distal angle, spinule at base (Figs 3A, 4B). Major cheliped palm length about $1.2-1.4 \times$ height in males $(\mathrm{n}=5)$, $1.3 \times$ in female $(n=1)$; dactylus $0.9-1.0 \times$ palm length in males $(n=5), 0.9 \times$ in female $(n=1)$ (Fig. 5G, I). Palm surface pitted, dorsal-outer surface granulated in larger 


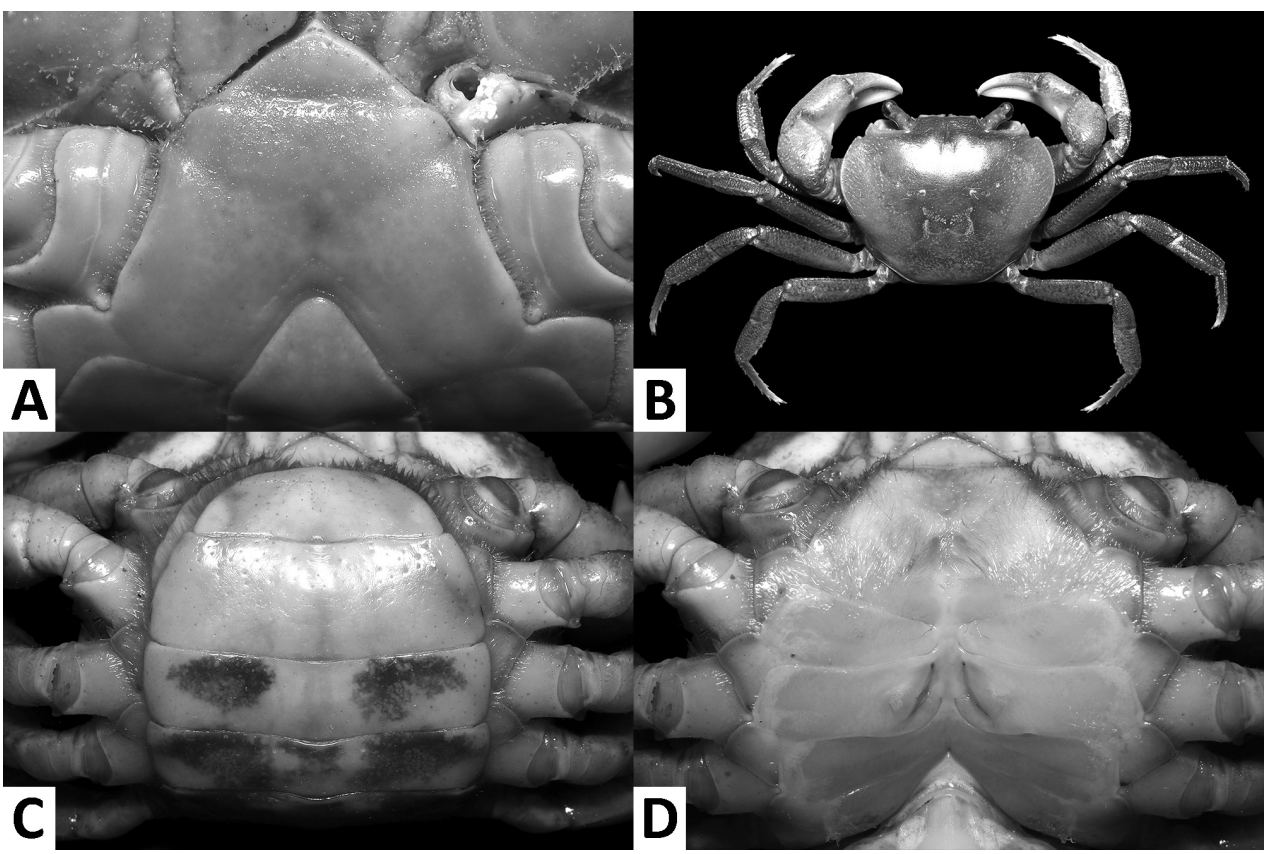

Figure 4. Nanhaipotamon macau sp. n., male holotype $(37.4 \times 30.9$ mm), SYSBM 001649 (A); female paratype $(31.3 \times 25.5 \mathrm{~mm})$, SYSBM 001650 (B-D). Anterior thoracic sternum $(\mathbf{A})$; dorsal habitus $(\mathbf{B})$; pleon, ventral view $(\mathbf{C})$; vulvae, ventral view $(\mathbf{D})$.

males (Fig. 5G). Dactylus as long as pollex (Fig. 5F-I). Occlusal margin of fingers with irregular blunt teeth; slight gape when closed (Fig. 5F-I).

Ambulatory legs (pereiopods II-V) slender, setae short, very sparse (Figs 3A, 4B). Pereiopod III merus 0.6-0.7 $\times$ carapace length in males $(n=5), 0.6 \times$ carapace length in female $(n=1)$ (Figs $3 A, 4 B)$. Pereiopods $V$ propodus $2.1-2.2 \times$ as long as broad in males $(\mathrm{n}=5), 2.1 \times$ as long as broad in female $(\mathrm{n}=1)$, shorter than dactylus (Figs 3A, 4B).

Male thoracic sternum generally smooth; sternites I-IV narrow, width about 1.5 $\times$ length; sternites I, II forming triangular structure; sternites II, III fused, but demarcated by shallow transverse sulcus; sternites III, IV fused, demarcation inconspicuous (Fig. 4A). Male sterno-pleonal cavity reaching anteriorly beyond level of posterior articular condyle of cheliped coxa (Fig. 4A); deep median longitudinal groove between sternites VII, VIII (Fig. 3D). Male pleonal locking tubercle positioned at mid-length of sternite $\mathrm{V}$ (Fig. 3D). Female vulva ovate, medium-sized, not reaching the sutures of sternites V/VI or VI/VII, positioned closely to one another (Fig. 4D).

Male pleon triangular; somites III-VI progressively narrower, lateral margins almost straight; somite VI width 1.8-2.1 $\times$ length $(\mathrm{n}=6)$; telson width $1.3-1.4 \times$ length $(\mathrm{n}=6)$; apex rounded (Fig. 3C). Female pleon broadly ovate (Fig. 4C).

G1 slender; in-situ, tip of terminal segment exceeding pleonal locking tubercle, almost reaching suture between thoracic sternites IV/V (Fig. 3D); subterminal segment length about $3.1 \times$ length of terminal segment; subterminal segment tapering distally; 
terminal segment large, distally expanded, distal margin laminar, slightly sinuous to V-shaped, apex blunt, directed outward, orientation perpendicular to oblique to main axis of G1 (Figs 5C-E, 6A-C). G2 subterminal segment about $1.9 \times$ length of flagelliform distal segment; exopod absent (Fig. 5B).

Etymology. This species is named after the type locality, Macau; used as a noun in apposition.

Colour in life. Variable, carapace and ambulatory legs dark brown to purple; chelipeds a combination of brown, orange and white (Fig. 2A).

Habitat. Nanhaipotamon macau sp. n. is a typical semi-terrestrial species that burrows in wet soil in the bank adjacent to hill streams. It was sympatric with Cantopotamon hengqinense at three localities $(22.117 \mathrm{~N}, 113.566 \mathrm{E} ; 22.118 \mathrm{~N}, 113.559 \mathrm{E}$; $22.128 \mathrm{~N}, 113.561 \mathrm{E})$.

Distribution. Coloane, Macau.

Remarks. As with many other species of Nanhaipotamon, N. macau sp. n. shows intraspecific variation in G1 morphology. In the terminal segment, the curves of the inner-distal and distal margins vary (Fig. 5C-E). The general shape and large size of the terminal segment, however, readily separates $N$. macau from other congeners in the Pearl River Delta Region, such as N. guangdongense Dai, 1997 (Fig. 7).

Nanhaipotamon wupingense Cheng, Yang, Zhong \& Li, 2003, from Fujian Province, is the only other known congener that also possesses such a large terminal segment. Based on the redscription of $N$. wupingense below, $N$. macau sp. n. differs by its larger maximum size (CW to $37.4 \mathrm{~mm}$ vs $27.5 \mathrm{~mm}$ in $N$. wupingense; Cheng et al. 2003); more inflated and less rugose branchial regions (compare Figs 3A, B, 8A, B); pterygostomial region granules larger, less numerous (compare Figs 3B, 8B); the G1 tip usually points laterally and the convex anterior margin next to the tip is often lower (Figs 5C-E, 6A-C) (tip points anterolaterally with higher adjacent convex margin, Fig. 6D; Cheng et al. 2003: fig. 7); G1 subterminal segment length about 3.0-3.2 $\times$ length of terminal segment in $N$. macau sp. n. (Figs 5C-E, 6A) (2.7 in the neotype of N. wupingense, see below, Fig. 6D). In keeping with their wide geographic separation, sequences of the COI barcoding region between $N$. macau sp. n. (SYSBM 001654; GenBank accession number MK226142) and $N$. wupingense (GenBank accession number: AB470511.1), courtesy of Hsi-Te Shih, shows a high (13.51\%) Kimura 2-parameter (K2P) distance, corroborating their separate species status.

Conservation status. Nanhaipotamon macau sp. n. has an extremely restricted distribution with an extent of occurrence of only $5.3 \mathrm{~km}^{2}$ (excluding sea area) and an area of occupancy of around $3 \mathrm{~km}^{2}$. However, all 12 hill streams at which $N$. macau sp. n. was found are not currently open to urban development (one of these, Ka-Ho Reservoir Freshwater Wetland, is a protected area) and they seem to be locally abundant. We are unaware of any commercial harvesting of these crabs for human consumption or the aquarium trade. As such, no imminent threats to this species are apparent and it cannot be assigned to any level of threat according the IUCN Red List criteria. However, we emphasize the fragility of this species due to its highly restricted distribution; the habitat integrity of the hills of Coloane is paramount to this species' survival. 


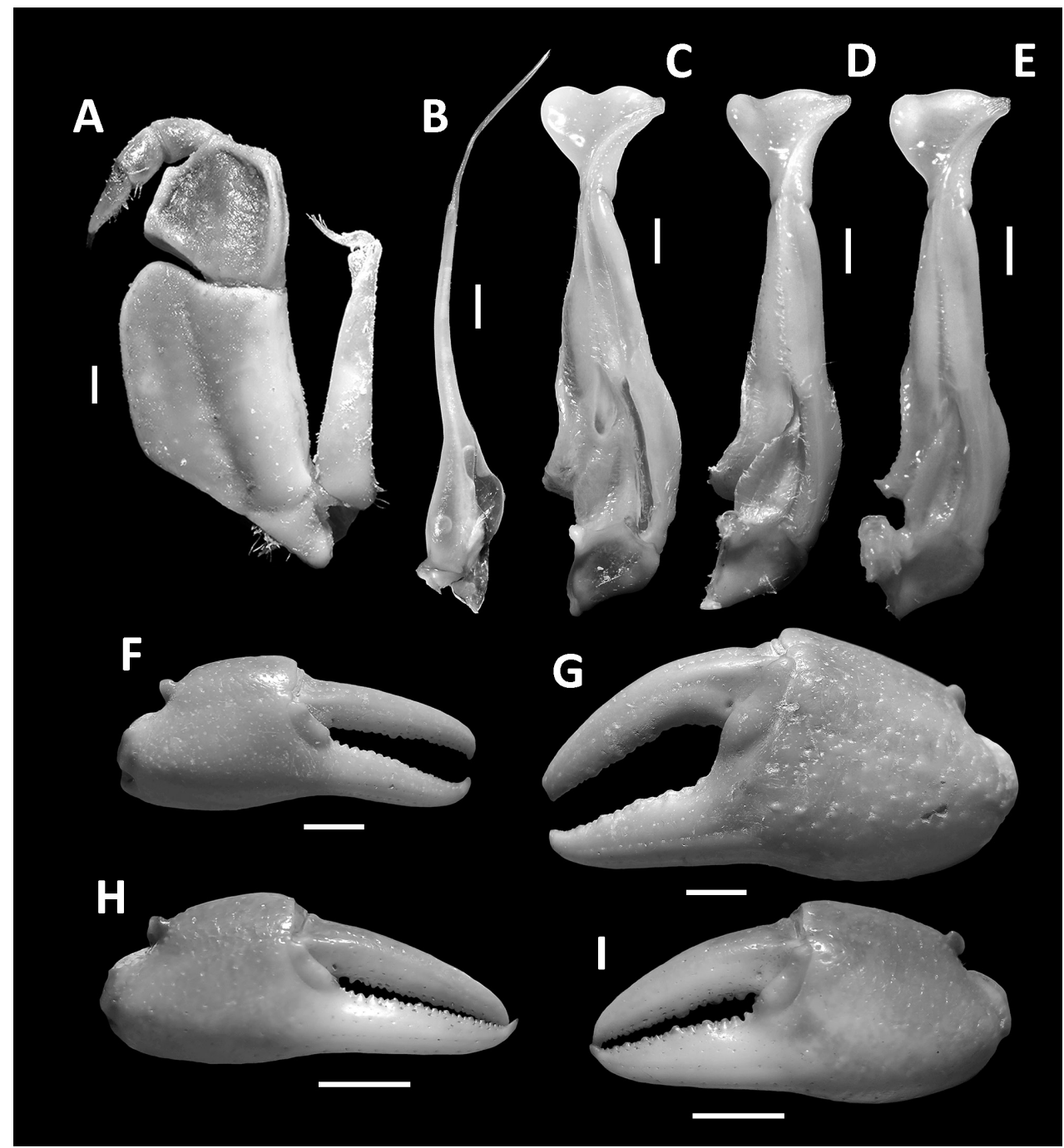

Figure 5. Nanhaipotamon macau sp. n., male holotype $(37.4 \times 30.9 \mathrm{~mm})$, SYSBM $001649(\mathbf{A}-\mathbf{C}, \mathbf{F}, \mathbf{G})$; male paratype $(36.6 \times 29.3 \mathrm{~mm})$, SYSBM 001651 (D); male $(35.3 \times 28.8 \mathrm{~mm})$, SYSBM $001652(\mathbf{E})$; female paratype $(31.3 \times 25.5 \mathrm{~mm})$, SYSBM $001650(\mathbf{H}-\mathbf{I})$. Left maxilliped 3 (A); left G2, ventral view (B); left G1, ventral view $(\mathbf{C}-\mathbf{E})$; minor cheliped $(\mathbf{F}, \mathbf{H})$; major cheliped $(\mathbf{G}, \mathbf{I})$. Scale bars: $1.0 \mathrm{~mm}(\mathbf{A}-\mathbf{E}) ; 5.0 \mathrm{~mm}(\mathbf{F}-\mathbf{I})$.

\section{Nanhaipotamon guangdongense Dai, 1997}

Figs 2B, 6G, 7

Nanhaipotamon guangdongense Dai, 1997: 229, fig. 9; Dai 1999: 121, pl. 8(1), fig. 60; Huang et al. 2012: 57, fig. 1A, 60; fig. 4, 61; fig. 5A-C.

Type material. Holotype: AS-CB 05141, male $(33.2 \times 26.4 \mathrm{~mm})$, Guangdong Province, China, gift from Sun Yat-Sen Medical College, no date [photographs examined]. 
Other material examined. SYSU 001001, male $(38.5 \times 30.0 \mathrm{~mm})$, Xiangzhou (22.25N, 113.57E), Zhuhai City, Guangdong, blue, mud hole next to small hillstream, coll. C. Huang, May 2012. SYSBM 001003, 1 male $(36.2 \times 28.4 \mathrm{~mm})$, Xiangzhou, Zhuhai City, Guangdong, mud hole next to small hill stream, coll. C. Huang, February 2011. SYSBM 001004, 1 male $(30.5 \times 24.3 \mathrm{~mm})$, Xiangzhou, Zhuhai City, Guangdong, mud hole next to small hill stream, coll. C. Huang, August 2012. SYSBM 001177, 1 male $(35.4 \times 29.4 \mathrm{~mm})$, Xiangzhou, Zhuhai City, Guangdong, mud hole next to small hill stream, coll. C. Huang, May 2013. SYSBM 001178, 1 female, $(35.9 \times 29.4 \mathrm{~mm})$, same data as above. SYSU 001758-001760, 3 males (40.1 $\times 32.7 \mathrm{~mm}, 36.0 \times 29.8 \mathrm{~mm}, 30.2 \times 25.1 \mathrm{~mm}$ ), Xiangzhou, Zhuhai City, Guangdong, blue, mud hole next to small hillstream, coll. C. Huang, September 2018. SYSU 001761-001764, 4 males $(42.1 \times 33.5 \mathrm{~mm}, 40.5 \times 32.4 \mathrm{~mm}, 38.1 \times 32.0 \mathrm{~mm}, 32.5 \times$ $27.0 \mathrm{~mm}$ ), Xiangzhou, Zhuhai City, Guangdong, mud hole next to small hill stream, coll. C. Huang, September 2018. SYSBM 001141-001143, 3 males $(38.4 \times 31.5$ $\mathrm{mm}, 40.8 \times 32.2 \mathrm{~mm}, 36.7 \times 29.4 \mathrm{~mm})$, Gujing $(22.36 \mathrm{~N}, 113.12 \mathrm{E})$, Jiangmen City, Guangdong, coll. local, August 2013. IACM, 2 males $(39.5 \times 31.5 \mathrm{~mm}, 25.2 \times 21.1$ $\mathrm{mm})$, Taipa $(22.16 \mathrm{~N}, 113.58 \mathrm{E})$, Macau, mud hole next to small hill stream, coll. K.C. Wong, March 2018. SYSBM 001645-001646, 2 males $(35.9 \times 28.8$ mm, $30.9 \times 24.8$ $\mathrm{mm}$ ), Taipa, Macau, mud hole next to small hill stream, coll. C. Huang, June 2018. SYSBM 001656, 1 male $(45.5 \times 37.0 \mathrm{~mm})$, Dahengqin mountain $(22.11 \mathrm{~N}, 113.50 \mathrm{E})$, Hengqin Island, Zhuhai City, Guangdong, in small hill stream pool, coll. C. Huang, August 2017. SYSBM 001672, 1 male $(22.4 \times 18.5 \mathrm{~mm})$, Jinwan (22.08N, 113.35E), Zhuhai City, Guangdong, mud hole next to small hill stream, coll. C. Huang, June 2018. SYSBM 001673-001674, 2 females $(31.7 \times 25.7 \mathrm{~mm}, 25.9 \times 20.8 \mathrm{~mm})$, same data as above. SYSBM 001017-001019, 3 males $(33.4 \times 26.5 \mathrm{~mm}, 29.2 \times 23.6 \mathrm{~mm}$, $27.6 \times 21.7 \mathrm{~mm})$, Doumen (22.19N, 113.29E), Zhuhai City, Guangdong, coll. local, April 2013. SYSBM 001657-001658, 2 males $(36.9 \times 30.4 \mathrm{~mm}, 23.0 \times 19.5 \mathrm{~mm})$, Jinzhong Reservoir (22.48N, 113.38E), Zhongshan City, Guangdong, mud hole next to small hill stream, coll. C. Huang, January 2018. SYSBM 001659, 1 female (23.6 $\times 19.8)$, same data as above. SYSBM 001016, 1 male $(40.5 \times 33.1 \mathrm{~mm})$, Qi ao Island (22.43N, 113.66E), Zhuhai City, Guangdong, mud hole next to small hill stream, coll. C. Huang, May 2011. SYSBM 001023, 1 female $(40.5 \times 33.1 \mathrm{~mm})$, same data as above. SYSBM 001750, 1 male $(39.6 \times 32.5 \mathrm{~mm})$, Gudou Mountain $(22.22 \mathrm{~N}$, 112.97E), Jiangmen City, Guangdong, coll. local, July 2018. SYSBM 001751, 1 male $(35.1 \times 26.0 \mathrm{~mm})$, Xinhui (22.52N, 113.08E), Jiangmen City, Guangdong, coll. local, July 2018.

Colour in life. Highly variable, even within the same population. Carapace and ambulatory legs dark brown to purple; chelipeds a combination of brown, orange and white (Fig. 2B). Blue variants are sometimes seen.

Distribution. Guangdong: Zhuhai, Zhongshan, Jiangmen; Macau: Taipa.

Remarks. Nanhaipotamon guangdongense has been found at only one locality in Macau (Tai Tam Hill, Taipa). One specimen (SYSBM 001646) has exopods on the G2 on both sides, the first such report for a freshwater crab (Fig. 6G). The G2 exopod is 


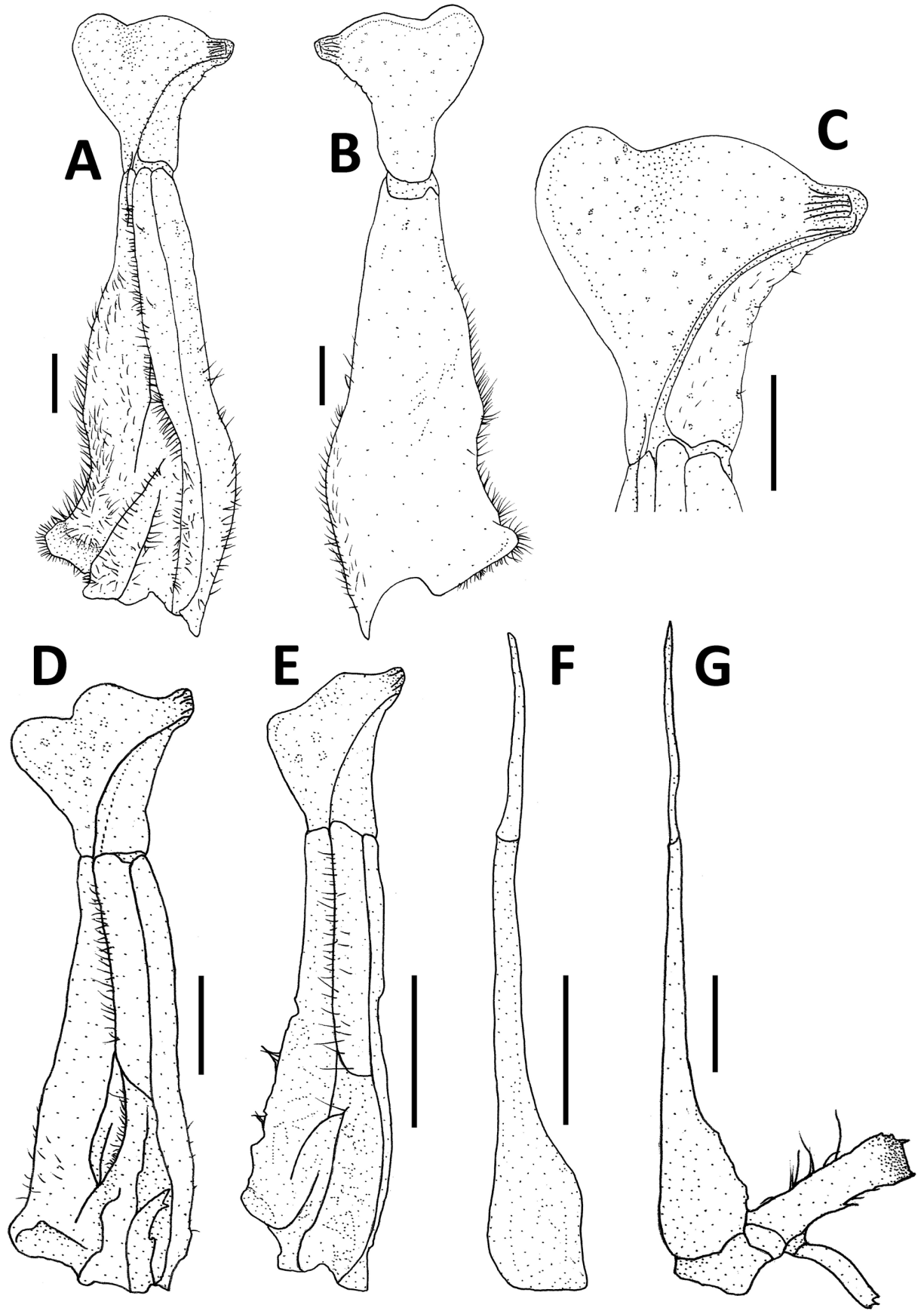

Figure 6. Nanhaipotamon macau sp. n., male holotype (37.4 × 30.9 mm), SYSBM 001649 (A-C); Nanhaipotamon wupingense Cheng, Yang, Zhong \& Li, 2003, male neotype $(22.4 \times 18.3 \mathrm{~mm})$, JX 050563 (D-F); Nanhaipotamon guangdongense Dai, 1997, male, (30.9 × 24.8 mm), SYSBM 001646 (G). Left G1, ventral view (A, D, E); left G1, dorsal view (B); Left G1 terminal segment, ventral view (C); Left G2, ventral view $(\mathbf{F}, \mathbf{G})$. Scale bar: $1.0 \mathrm{~mm}$. 
likely the result of a developmental abnormality and is an extremely rare occurrence (Gordon, 1963). The majority of brachyurans lack the male G2 exopod although it is being increasingly recognized as a normal feature among many pinnotherid crabs (Ahyong et al. 2012; Ng and Ho 2016).

Little was previously known about $N$. guangdongense as it was described from a single specimen without a precise locality. Attempts to sequence the DNA of $N$. guangdongense were unsuccessful, probably because of formalin fixation, compounding the problem of its identification (Shih et al. 2011). Huang et al. (2012) reported N. guangdongense from Zhuhai. Small differences in the G1 morphology, however, suggest the holotype of $N$. guangdongense was probably collected from another locality (Peter $\mathrm{Ng}$ pers. comm.). More recent collection efforts in Guangdong have found this species at multiple locations in Zhuhai, Zhongshan, and Jiangmen. Specimens from Gujing, Jiangmen (Fig. 7A-C) most closely resemble the holotype in G1 morphology suggesting that the holotype was probably collected from that area.

Normal and blue coloured Nanhaipotamon were sympatric at a locality in Xiangzhou, Zhuhai. Nanhaipotamon zhuhaiense Huang, Huang \& Ng, 2012 was described based on only three blue specimens that had a distinctive G1 that pointed laterally and not anterolaterally as seen in the normal coloured comparative specimens. More recent collections from Xiangzhou, Zhuhai, however, have found a normal coloured specimen that has a laterally pointing G1 (Fig. 7E) and also a blue specimen that has an anterolaterally pointing G1 (Fig. 7F). Therefore, the colouration of the crab does not always correspond to a particular gonopod morphology. Specimens of intermediate G1 morphology have also been collected, while one uncollected female specimen was observed to be of intermediate colour. Furthermore, the COI K2P distances between the blue specimens SYSBM 001001 (GenBank no: MK226143), SYSBM001249 (GenBank no: MK226144) and the normal coloured specimen SYSBM 001015 (GenBank no: MK226145) are $1.23 \%$ and $0.77 \%$ respectively, which is of intraspecific level among closely related congeners. This new evidence strongly suggests that the normal and blue coloured crabs are different colour phases of the same species, but the G1 morphological differences between different specimens remains to be further studied. This seems to be a similar case to that of $N$. hepingense Dai, 1977, and $N$. pinghense Dai, 1977 (see Shih et al. 2011; Huang et al. 2012). Given that we are unable to confidently separate $N$. zhuhaiense from $N$. guangdongense, we regard them as probably conspecific, but refrain from making formal taxonomic changes until further detailed comparisons can be completed.

The G1 of specimens of $N$. guangdongense from different localities varies (Fig. 7). It is becoming increasingly evident that intraspecific variation of gonopodal morphology in some species of Nanhaipotamon is wider than previously recognized, while external differences are often hard to detect between species, making the taxonomy of this genus problematic (Figs 5C-E, 7; Huang et al., 2012: fig. 5; unpublished data). Clearly, there is need for a revision of this genus. To avoid compounding the problem in the future, we strongly recommend that new species of Nanhaipotamon should only be described when a large series of specimens is available to account for intraspecific variation. 


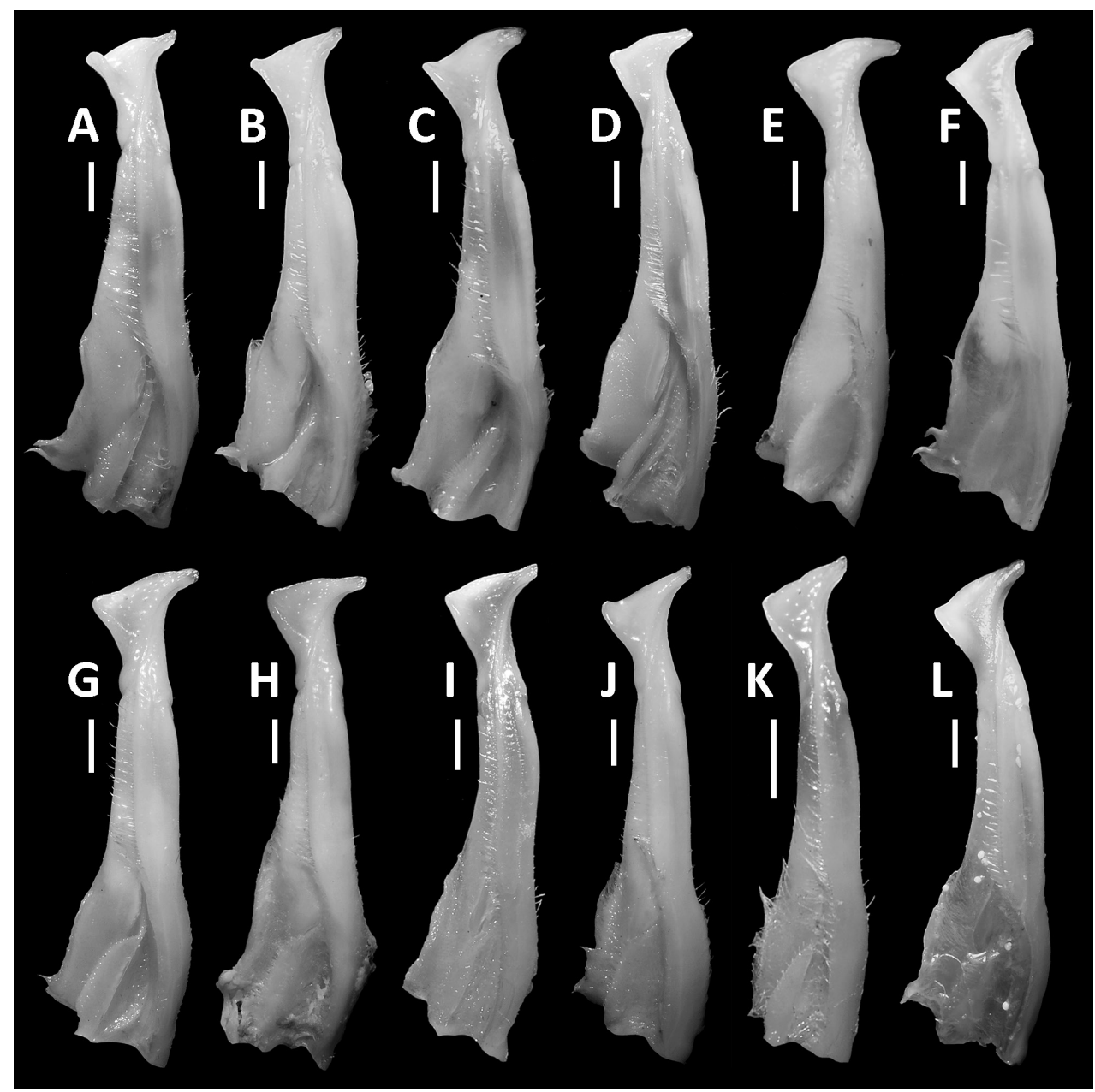

Figure 7. Comparison of G1 of Nanhaipotamon guangdongense Dai, 1997, from different localities. Male $(38.4 \times 31.5 \mathrm{~mm})$, SYSBM 001141, Gujing, Jiangmen $(\mathbf{A})$; male $(40.8 \times 32.2 \mathrm{~mm})$, SYSBM 001142, Gujing, Jiangmen (B); male $(36.7 \times 29.4 \mathrm{~mm})$, SYSBM 001143, Gujing, Jiangmen $(\mathbf{C})$; male $(35.4 \times$ $29.4 \mathrm{~mm})$, SYSBM 001177, Xiangzhou, Zhuhai (D); male $(32.5 \times 27.0 \mathrm{~mm})$, SYSBM 001764, Xiangzhou, Zhuhai $(\mathbf{E})$; male $(40.1 \times 32.7 \mathrm{~mm})$, SYSBM 001758, Xiangzhou, Zhuhai $(\mathbf{F})$; male $(35.9 \times 28.8$ $\mathrm{mm})$, SYSBM 001645, Coloane, Macau (G); male $(45.5 \times 37.0 \mathrm{~mm})$, SYSBM 001656, Hengqin Island, Zhuhai $(\mathbf{H})$; male $(22.4 \times 18.5 \mathrm{~mm})$, SYSBM 001672, Jinwan, Zhuhai $(\mathbf{I})$; male $(33.4 \times 26.5 \mathrm{~mm})$, SYSBM 001017, Doumen, Zhuhai (J); male $(36.9 \times 30.4 \mathrm{~mm})$, SYSBM 001657, Jinzhong Reservoir, Zhongshan $(\mathbf{K})$; male $(40.5 \times 33.1 \mathrm{~mm})$, SYSBM 001016, Qi'ao Island, Zhuhai (L). Scale bars: $1.0 \mathrm{~mm}$.

Conservation status. Nanhaipotamon guangdongense was previously assessed as Data Deficient, being known from one unspecified location in Guangdong (Cumberlidge 2008). This species is sometimes collected for food and for the pet trade, though we are uncertain as to the extent. Nevertheless, this species has been found in many locations with a wider range than previously thought, having an extent of occurrence of around 2,400 km² (excluding sea area) and an area of occupancy of around 1,600 
$\mathrm{km}^{2}$. As such, we suggest the conservation status of this species under IUCN criteria would be more appropriate as Least Concern (LC). Nevertheless, $N$. guangdongense is quite rare in Macau, being found in only one location in the Ecological Pond of Grand Taipa, and thus may warrant local conservation attention.

\section{Nanhaipotamon wupingense Cheng, Yang, Zhong \& Li, 2003 \\ Figs 6D-F, 8}

Nanhaipotamon wupingense Cheng, Yang, Zhong \& Li, 2003: 678, figs 1-8.

Type material. Neotype: JX 050563, male $(22.4 \times 18.3 \mathrm{~mm})$, Xiaba $(24.89 \mathrm{~N}$, 116.05E), Wuping county, Longyan City, Fujian Province, China, coll. X. M. Zhou, May 2007.

Other material examined. JX 050564, JX 050566, JX 050568-050569, 4 males $(16.2 \times 13.2 \mathrm{~mm}, 15.5 \times 12.6 \mathrm{~mm}, 13.0 \times 10.9 \mathrm{~mm}, 14.0 \times 11.5 \mathrm{~mm})$, same data as neotype. JX 050565, JX 050567, JX 050570-050576, 9 females $(16.1 \times 13.2 \mathrm{~mm}$, $13.0 \times 10.5 \mathrm{~mm}, 25.3 \times 20.8 \mathrm{~mm}, 23.4 \times 19.5 \mathrm{~mm}, 24.9 \times 20.3 \mathrm{~mm}, 21.6 \times 17.6 \mathrm{~mm}$, $16.9 \times 13.7 \mathrm{~mm}, 14.8 \times 11.7 \mathrm{~mm}, 15.2 \times 12.4 \mathrm{~mm}$ ), same data as neotype.

Description. Carapace broader than long, width about $1.2 \times$ length $(\mathrm{n}=14)$; regions indistinct, dorsal surface convex; surface generally smooth, pitted, anterolateral region slightly rugose (Fig. 8A). Front deflexed, margin ridged in dorsal view (Fig. 8A). Epigastric cristae low, separated by narrow gap (Fig. 8A). Postorbital cristae sharp, laterally expanded, almost confluent with epibranchial teeth and epigastric cristae (Fig. 8A). Branchial regions slightly swollen (Fig. 8A, B). Cervical groove shallow (Fig. 8A). Mesogastric region slightly convex (Fig. 8A). External orbital angle sharply triangular, outer margin gently convex, separated from anterolateral margin by conspicuous gap (Fig. 8A, B). Epibranchial tooth small, granular, indistinct (Fig. 8A, B). Anterolateral margin cristate, lined with 17-20 granules, less distinct in some larger specimens; curved inward posteriorly (Fig. 8A). Posterolateral surface with low, oblique striae, converging towards posterior carapace margin (Fig. 8A). Orbits large; supraorbital, infraorbital margins cristate (Fig. 8B). Sub-orbital, pterygostomial and sub-hepatic regions covered with numerous rounded granules (Fig. 8B). Epistome posterior margin narrow; median lobe broadly triangular, lateral margins slightly sinuous (Fig. 8B).

Maxilliped III merus about as wide as long; ischium width about $0.7 \times$ length; merus subtrapezoidal, with median depression; ischium subtrapezoidal, with distinct median sulcus, mesial margin rounded. Exopod reaching to proximal one-third of merus; flagellum short.

Chelipeds (pereiopod I) unequal (Fig. 8A); less inflated in females. Merus trigonal in cross section; margins crenulated, dorsal-outer surface granulated (Fig. 8A). Carpus with sharp spine at inner-distal angle, spinule at base (Fig. 8A). Major cheliped palm length about $1.3 \times$ height $(\mathrm{n}=1)$ in males, $1.3-1.4 \times$ height $(\mathrm{n}=4)$ in females; dactylus about $1.0 \times$ palm length $(n=1)$ in males, $1.0-1.1 \times$ palm length $(n=4)$ in females. 


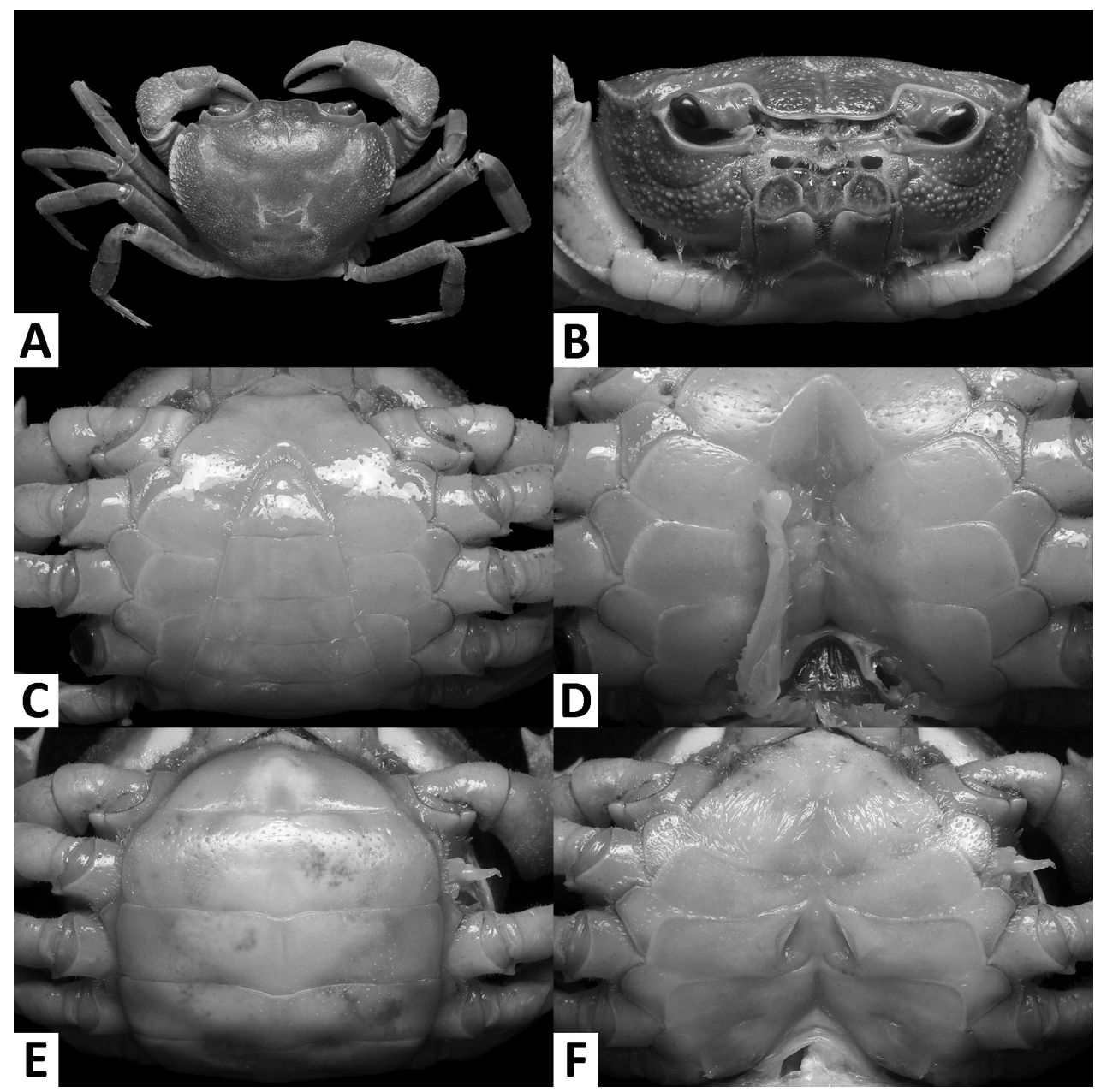

Figure 8. Nanhaipotamon wupingense Cheng, Yang, Zhong \& Li, 2003, male neotype $(22.4 \times 18.3 \mathrm{~mm})$, JX 050563 (A-D); female $(25.3 \times 20.8$ mm), JX 050570 (E-F). Dorsal habitus (A); cephalothorax, anterior view (B); anterior thoracic sternum and pleon, ventral view $(\mathbf{C})$; sterno-pleonal cavity with right G1 in situ (left G1 removed), ventral view (D); pleon, ventral view (E); vulvae, ventral view (F).

Palm surface pitted. Dactylus as long as pollex (Cheng et al. 2003: fig. 1). Occlusal margin of fingers with irregular blunt teeth; slight gape when closed.

Ambulatory legs (pereiopods II-V) slender, setae short, very sparse (Fig. 8A). Pereiopod III merus $0.6 \times$ carapace length $(\mathrm{n}=3)$ in males, $0.6-0.7 \times$ carapace length $(\mathrm{n}=7)$ in females (Fig. 8A). Pereiopods $V$ propodus $2.3-2.4 \times$ as long as broad in males $(\mathrm{n}=3), 2.3-2.4 \times$ as long as broad in females $(\mathrm{n}=5)$, shorter than dactylus (Fig. 8A).

Male thoracic sternum generally smooth; anterior thoracic sternum (sternites I-IV) narrow, width about $1.5 \times$ length; sternites I, II forming triangular structure; demarcation between sternites II, III complete; sternites III, IV fused with vestigial median suture (Fig. 8C). Male sterno-pleonal cavity reaching anteriorly beyond level 
of posterior articular condyle of cheliped coxa (Fig. 8C); deep median longitudinal groove between sternites VII, VIII (Fig. 8D). Male pleonal locking tubercle positioned at mid-length of sternite $\mathrm{V}$ (Fig. 8D). Female vulva ovate, not reaching the sutures of sternites V/VI or VI/VII, positioned closely to one another (Fig. 8F).

Male pleon triangular, lateral margins almost straight; somites III-VI progressively narrower; somite VI width 2.1-2.2 $\times$ length $(\mathrm{n}=2)$; telson width $1.2-1.3 \times$ length $(n=2)$; apex rounded (Fig. 8C). Female pleon broadly ovate (Fig. 8E).

G1 slender; in-situ, tip of terminal segment exceeding pleonal locking tubercle, reaching suture between thoracic sternites IV/V (Fig. 8D, G1 not flat against the body); subterminal segment length about $2.7 \times$ length of terminal segment; subterminal segment tapering posteriorly; terminal segment large, distally expanded, anterior margin laminar, convex anterior margin next to the tip high, tip blunt (Fig. 6D, E). G2 subterminal segment about $2.1 \times$ length of flagelliform distal segment; exopod absent $(6 \mathrm{~F})$.

Distribution. Currently only known from Xiaba, Wuping County, Longyan City, Fujian.

Remarks. The original description of Nanhaipotamon wupingense is brief and minimally illustrated (Cheng et al. 2003), neither describing nor figuring details of the carapace physiognomy and pterygostomial ornamentation, which are diagnostic differences between $N$. wupingense and $N$. macau sp. n. Although the gonopods of $N$. wupingense were described and figured, and were distinctive at the time of original description, they are similar to that to the newly discovered $N$. macau sp. n. As such the type account of $N$. wupingense could apply equally to $N$. macau sp. n. Unfortunately, the type material of $N$. wupingense is now lost: according to the first author of $N$. wupingense, the type material of $N$. wupingense, which was originally deposited in Fujian Research Institute of Parasite Disease, Fuzhou, Fujian Province, was lost during relocation (YZ Cheng, pers. comm.). Therefore, in order to fix the identity of $N$. wupingense and allow adequate characterization of both species, we hereby designate a neotype for $N$. wupingense in accordance to ICZN (1999: art. 75.3). The neotype of $N$. wupingense (male, $22.4 \times 18.3 \mathrm{~mm}$, JX 050563) and other examined specimens of the species were collected from the original type locality. The neotype G1 corresponds well to that originally described and figured for $N$. wupingense, although we note some minor differences in morphometrics compared to the original type description (Cheng et al. 2003). The G1 subterminal/terminal segment length ratio of $N$. wupingense is 3.0 according to Cheng et al. (2003), but, we measure the ratio at 2.7 in the neotype (Fig. 6D) and 2.6 based on the illustration of the G1 of the holotype (Cheng et al. 2003: fig. 7). The G2 subterminal/terminal segment length ratio of $N$. wupingense is inconsistently recorded in Cheng et al. (2003): 1.8 in the Chinese description, erroneously as 2.7 in the English abstract, and 2.0 if based on the figure of the holotype G2 (Cheng et. al. 2003: fig. 6). This ratio could not be measured for the neotype as the G2 terminal segment broke off inside the G1 during dissection, although the ratio in JX 050564, a sub-adult, is 2.2 (Fig. 6F). The G1 is not fully developed in this specimen (Fig. 6E). 


\section{Family Gecarcinucidae Rathbun, 1904 \\ Genus Somanniathelphusa Bott, 1968}

\section{Somanniathelphusa zanklon Ng \& Dudgeon, 1992}

Figs 2D, 9

Somanniathelphusa zanklon Ng \& Dudgeon, 1992: figs 11-13.

Parathelphusa sinensis: Doflein 1902: 662.

Parathelphusa (Parathelphusa) sinensis: Gee 1925: 159; Wu 1934: 339.

Somanniathelphusa sinensis sinensis: Bott 1968b: 409, figs 11, 12, 30; Bott 1970a: 338;

Bott 1970b: 111, pl. 20, figs 42-44; Ng, 1988: 105.

Somanniathelphusa sinensis: Dai 1999: 67, fig. 29, pl. 2.

Material examined. SYSBM 101001, 1 male $(27.2 \times 23.1 \mathrm{~mm})$, Nanping $(22.19 \mathrm{~N}$, 113.5E), Zhuhai City, Guangdong, reservoir, coll. C. Huang, April 2015. SYSBM $101002-101003,2$ males $(38.8 \times 31.9 \mathrm{~mm}, 30.4 \times 25.6 \mathrm{~mm})$, Jinding $(22.38 \mathrm{~N}$, 113.54E), Zhuhai City, Guangdong, coll. local, May 2014. SYSBM 101004-101005, 2 males $(42.0 \times 33.5 \mathrm{~mm}, 34.2 \times 28.1 \mathrm{~mm})$, Sun Yat-sen University $(23.10 \mathrm{~N}, 113.30 \mathrm{E})$, Guangzhou City, Guangdong, fish pond, coll. C. Huang, June 2013. SYSBM 101006, 1 female $(37.1 \times 29.5 \mathrm{~mm})$, same data as above. SYSBM 101007, 1 male $(30.6 \times 24.5$ mm), Coloane (22.12N, 113.56E), Macau, reservoir, coll. K.C. Wong, July 2008. SYSBM 101008, 1 male $(28.2 \times 22.5 \mathrm{~mm})$, Coloane, Macau, reservoir, coll. K.C. Wong, July 2009. IACM, 1 male $(24.2 \times 19.8 \mathrm{~mm})$, Coloane, Macau, reservoir, coll. K.C. Wong, February 2013. SYSBM 101009-101010, 2 males $(19.5 \times 16.8$ mm, 19.2 $\times 16.4 \mathrm{~mm})$, Shenzhen City (22.6N, 114.0E), Guangdong, coll. local, August 2015 . SYSBM 101011, 1 female $(19.6 \times 16.4 \mathrm{~mm})$, same data as above. SYSBM 101015101016, 2 males $(35.7 \times 28.4 \mathrm{~mm}, 37.2 \times 29.9 \mathrm{~mm})$, Sihui City $(23.12 \mathrm{~N}, 113.56 \mathrm{E})$, Guangdong, coll. local, August 2013. SYSBM 101017, 1 female $(31.6 \times 25.9 \mathrm{~mm})$, same data as above. SYSBM 101018-101020, 3 males $(38.2 \times 30.8 \mathrm{~mm}, 35.4 \times 28.1$ mm, $28.3 \times 21.3 \mathrm{~mm}$ ), Renhua, Shaoguan City, Guangdong, coll. local, August 2013 . SYSBM 101021, 1 male $(31.5 \times 26.6$ mm $)$, Lianhua Mountain, Shanwei City, Guangdong, coll. local, October 2013. SYSBM 101022, 1 female $(27.3 \times 23.2 \mathrm{~mm})$, same data as above. SYSBM 101030, 1 male $(39.4 \times 33.0 \mathrm{~mm})$, Heyuan City, Guangdong, coll. Z.C. Zhou, January 2014. SYSBM 101031, 1 female $(32.4 \times 27.3 \mathrm{~mm})$, same data as above. SYSBM 101032-101035, 4 males $(35.0 \times 28.3 \mathrm{~mm}, 32.7 \times 26.9 \mathrm{~mm}$, $30.8 \times 25.0$ mm, $25.9 \times 21.7 \mathrm{~mm}$ ), Raoping, Chaozhou City, Guangdong, coll. Z.C. Zhou, January 2014. SYSBM 101036, 1 female $(24.6 \times 20.8 \mathrm{~mm})$, same data as above. SYSBM 101037-101040, 4 males $(26.3 \times 20.4 \mathrm{~mm}, 30.9 \times 25.8 \mathrm{~mm}, 26.6 \times 23.0$ $\mathrm{mm}, 27.0 \times 22.5 \mathrm{~mm}$ ), Wenzhou City, Zhejiang, coll. local, October 2013. SYSBM 101041,1 female $(29.8 \times 24.6 \mathrm{~mm})$, same data as above.

Colour in life. Generally brown overall; larger individuals may have dark markings near the cardiac region (Fig. 2D). 


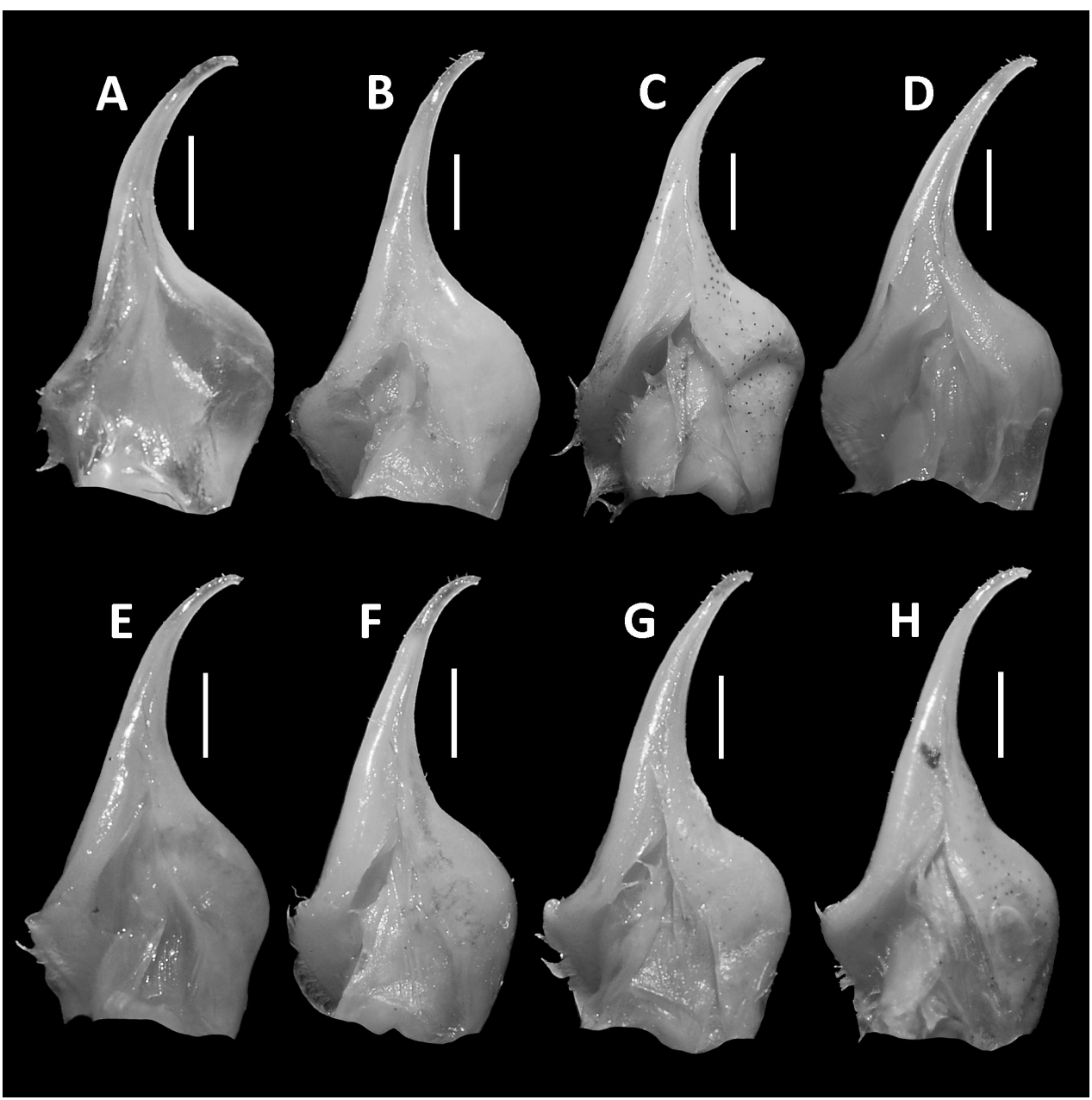

Figure 9. Comparison of G1 of Somanniathelphusa zanklon $\mathrm{Ng} \&$ Dudgeon, 1992, from different localities. Male $(30.6 \times 24.5 \mathrm{~mm})$, SYSBM 101007, Coloane, Macau $(\mathbf{A})$; male $(38.8 \times 31.9 \mathrm{~mm})$, SYSBM 101002, Jinding, Zhuhai City, Guangdong (B); male $(42.0 \times 33.5$ mm), SYSBM 101004, Sun Yat-sen University, Guangzhou City, Guangdong $(\mathbf{C})$; male $(35.7 \times 28.4 \mathrm{~mm})$, SYSBM 101015, Sihui City, Guangdong (D); male $(28.3 \times 21.3 \mathrm{~mm})$, SYSBM 101020, Renhua, Shaoguan City, Guangdong (E); male $(31.5 \times 26.6 \mathrm{~mm})$, SYSBM 101021, Lianhua Mountain, Shanwei City, Guangdong (F); male (35.0 $\times 28.3 \mathrm{~mm}$ ), SYSBM 101032, Raoping, Chaozhou City, Guangdong $(\mathbf{G})$; male $(26.3 \times 20.4 \mathrm{~mm})$, SYSBM 101037, Wenzhou City, Zhejiang $(\mathbf{H})$. Scale bars: $1.0 \mathrm{~mm}$.

Distribution. Coloane, Macau; Guangdong: Guangzhou City, Shenzhen City, Zhuhai City, Sihui City, Shaoguan City, Shanwei City, Heyuan City, Chaozhou City; Zhejiang: Wenzhou City.

Remarks. Ng and Dudgeon (1992) showed former records of Somanniathelphusa sinensis (H. Milne Edwards, 1853) from southern China (Bott 1968, 1970; Dai 1999) to represent a new species, S. zanklon. Shih et al. (2007) included S. zanklon from Hong Kong and Guangdong (Dongguan City and Nanhai City) and showed that specimens 
of Somanniathelphusa from eastern Guangdong, Fujian and west-central Taiwan were all very closely related genetically, probably even conspecific. Specimens examined here from different localities were all very similar morphologically (Fig. 9), with those from Zhejiang Province having a slightly longer G1 distal part (Fig. 9H), though the overall shape is very much like the others. We tentatively treat all of these as the same species pending a full revision. Interestingly, Dai (1999) also reported the genus from Zhejiang, but none of the species of Somanniathelphusa in her monograph lists Zhejiang among its localities. The Chinese Somanniathelphusa are particularly problematic as many species look identical externally and were described based on minute differences that we find difficult to detect. Furthermore, being lowland species, they are readily dispersed by floods and are commonly found in aquaculture ponds where their newly hatched crablings are easily translocated. Preliminary genetic evidence suggests that the species diversity of Somanniathelphusa may have been overestimated (Shih et al. 2007).

Conservation status. Somanniathelphusa zanklon is currently assessed as Endangered (Esser and Cumberlidge 2008) as it was known from fewer than five locations in Hong Kong with a extant of occurrence less than $5,000 \mathrm{~km}^{2}$, with degrading habitat quality. Our study, however, finds this species to have a widespread occurrence in south-east China with an area of occupancy estimated at over $120,000 \mathrm{~km}^{2}$. Though habitat quality in some of these locations is declining, this resilient lowland species seems to be able to thrive in most water bodies that are not heavily polluted. As such, we find that $S$. zanklon does not satisfy any IUCN Red List threat categories and thus we suggest Least Concern would be a more appropriate determination at present. In Macau, all known occurrences of S. zanklon are from Hac-Sa Reservoir, Coloane, although it most likely also occurs in other water bodies in Coloane. There was an unconfirmed sighting of S. zanklon in Taipa a few years ago by the second author, though more recent surveys have failed to locate any specimens. There are three large water bodies on the Macau peninsula, of which only one reservoir on the east, next to Parque Municipal do Monte da Guia, which sources freshwater from the mainland, is suitable for lowland freshwater crabs. Although we did not survey this reservoir, it very likely also holds $S$. zanklon as this species was found in one of its water source reservoirs in Zhuhai. The other two water bodies, Sai Van Lake and Nam Van Lake, were once bays that have mostly been artificially closed off by landfill and currently hold sea water.

\section{Acknowledgements}

This project was partly funded by the PANGEA research centre student grants program (UNSW) to the first author. Special thanks are expressed to XM Zhou, JX Zou, and their students (Nanchang University) for assisting the first author in examining specimens at Nanchang University, and to ZC Zhou for his donations of several Somanniathelphusa specimens. We would also like to acknowledge H-T Shih for providing genetic sequences for use in this study, and to Tohru Naruse, Savel R. Daniels and the editors for greatly improving the manuscript. 


\section{References}

Ahyong ST, Komai T, Watanabe T (2012) First Viridotheres Manning, 1996, from Japan, with a key to the species (Decapoda, Brachyura, Pinnotheridae). Studies in Malacostraca: a homage to Masatsune Takeda. Crustaceana Monographs 17: 35-47. https://doi. org/10.1163/9789004202894_003

Bott R (1968a) Potamiden aus Süd-Asien (Crustacea, Decapoda). Senckenbergiana biologica 49: 119-130.

Bott R (1968b) Parathelphusiden aus Hinterindien (Crustacea, Decapoda, Parathelphusidae). Senckenbergiana biologica 49: 403-422.

Bott R (1970a) Betrachtungen iiber entwicklungsgeschichte der Siisswasserkrabben nach der Sammlung des Naturhistorischen Museums in Genf/Schweiz. Revue Suisse (Zoologie) 77: 327-344. https://doi.org/10.5962/bhl.part.75900

Bott R (1970b) Dis Siisswasserkrabben von Europa, Asien, Australien und ihre Stammesgeschichte. Eine Revision der Potamoidea und Parathelphusoidea (Crustacea, Decapoda). Abhandlungen Senckenbergischen Naturforschenden Gesellschaft 526: 1-338.

Cheng YZ, Yang WC, Zhong YH, Li L (2003) A new species of the genus Nanhaipotamon (Decapoda: Potamid). Journal of Xiamen University (Natural Science) 42: 676-678.

Cumberlidge N (2008) Nanhaipotamon guangdongense. The IUCN Red List of Threatened Species 2008: e.T135072A4066344.

Dai AY (1997) A revision of freshwater crabs of the genus Nanhaipotamon Bott, 1968 from China (Crustacea: Decapoda: Brachyura: Potamidae). Raffles Bulletin of Zoology 45(2): 209-235.

Dai AY (1999) Fauna Sinica: Arthropoda Crustacea Malacostraca Decapoda Parathelphusidae Potamidae, Science Press, Beijing, 501 pp.

Davie PJ, Guinot D, Ng PKL (2015) Systematics and classification of Brachyura. In: Castro P, Davie PJF, Guinot D, Schram FR, Von Vaupel Klein JC (Eds) Treatise on zoology - anatomy, taxonomy, biology. The Crustacea 9C-I: 1049-1130. https://doi. org/10.1163/9789004190832_021

Doflein F (1902) Ostasiatische Dekapoden. Abhandlungen k. bayerischen Akademie Wissenschaft (2)21: 613-670. https://doi.org/10.1163/9789004190832_021

Esser L, Cumberlidge N (2008) Somanniathelphusa zanklon. The IUCN Red List of Threatened Species 2008: e.T134062A3888493.

Gee NG (1925) Tentative list of Chinese decapod Crustacea, including those represented in the collections of the United States National Museum (marked with an *) with localities at which collected. Lignan Agricultural Review 3: 156-166.

Gordon I (1963) An anomalous adult male spider crab with five pairs of pleopods. Crustaceana 5: 151-154. https://doi.org/10.1163/156854063X00426

Government of Macao Special Administrative Region Statistics and Census Service (2018) https://www.dsec.gov.mo/Statistic.aspx?NodeGuid=7bb8808e-8fd3-4d6b-904a$34 \mathrm{fe} 4 \mathrm{~b} 302883$ 
Huang C, Huang JR, Ng PKL (2012) A new species of Nanhaipotamon Bott, 1968 (Crustacea: Decapoda: Brachyura: Potamidae) from Zhuhai, Guangdong Province, China. Zootaxa 3588: 55-63.

Huang C, Shih HT, Ahyong ST (2017) Cantopotamon a new genus of freshwater crabs from Guangdong, China, with descriptions of four new species (Crustacea: Decapoda: Brachyura: Potamidae). Zoological Studies 56: 41. https://doi.org/10.6620/ZS.2017.56-41.

Kemp S (1918) Zoological results of a tour in the Far East. Decapod and stomatopod Crustacea. Memoirs of the Asiatic Society of Bengal 6(5): 221-297.

Kimura M (1980) A simple method for estimating evolutionary rates of base substitutions through comparative studies of nucleotide sequences. Journal of Molecular Evolution 16: 111-120. https://doi.org/10.1007/BF01731581

Milne Edwards H (1853) Observations sur les affinites zoologiques et la classification naturelle des Crustaces. Memoire sur la famille des Ocypodiens. Annales de Sciences Naturelle, Zoologie (3)20: 163-228.

Ng PKL, Dudgeon D (1992) The Potmidae and Parathelphusidae (Crustacea: Decapoda: Brachyura) of Hong Kong. Invertebrate Systematics 6(3): 741-768. https://doi.org/10.1071/ IT9920741

Ng PKL, Ho PH (2016) Orthotheres baoyu, a new species of pea crab (Crustacea: Brachyura: Pinnotheridae) associated with abalones from Tungsha Island, Taiwan; with notes on the genus. Raffles Bulletin of Zoology 64: 229-241. https://doi.org/10.11646/zootaxa.4433.1.13

Shen CJ (1940) Four new species of Brachyura from Chinese seas. Journal of the Hong Kong Fisheries Research Station 1: 255-62.

Shih HT, Chen GX, Wang LM (2005) A new species of freshwater crab (Decapoda: Brachyura: Potamidae) from Dongyin Island, Matsu, Taiwan, defined by morphological and molecular characters, with notes on its biogeography. Journal of Natural History 39(31): 2901-2911. https://doi.org/10.1080/00222930500214010

Shih HT, Fang SH, Ng PK (2007) Phylogeny of the freshwater crab genus Somanniathelphusa Bott, (Decapoda: Parathelphusidae) from Taiwan and the coastal regions of China, with notes on their biogeography. Invertebrate Systematics 21(1): 29-37. https://doi. org/10.1071/is06007

Shih HT, Zhou XM, Chen GX, Chien IC, Ng PKL (2011) Recent vicariant and dispersal events affecting the phylogeny and biogeography of East Asian freshwater crab genus Nanhaipotamon (Decapoda: Potamidae). Molecular Phylogenetics and Evolution 58(3): 427-438. https://doi.org/10.1016/j.ympev.2010.11.013

Tamura K, Stecher G, Peterson D, Filipski A, Kumar S (2013) MEGA6: Molecular Evolutionary Genetics Analysis Version 6.0. Molecular Biology and Evolution 30: 2725-2729. https://doi.org/10.1093/molbev/mst197 